\title{
Motivations in Developing inter-language Talk: A Study of Vocational College Business English Major
}

\author{
Jian-na Wang \\ Department of Foreign Language \\ Xi'an Fanyi University, Shaanxi 710105, China \\ 809392271@qq.com
}

\begin{abstract}
Motivation in second language learning is indispensable and significant. In order to improve the motivation in inter-language talk and develop oral English competence, this paper presented the study of motivation in inter-language and focused on how much the motivation in developing competence of inter-language talk is. It implements questionnaire and interview to one hundred and forty five vocational college business English majors from motivation orientation, desire, attitude and effort. After analyzing and discussing the data, the results demonstrate that business English majors in vocational college are motivated to develop their English competence in inter-language talk and they are or more intrinsically motivated than extrinsically motivated. And the conclusion can be drawn from the study that inter-language talk is an effective way to improve oral English and English learning achievement. It is original in this paper to study the business oral English from the perspective of interlanguage, which is new in second language learning in vocational collage.
\end{abstract}

Keywords-motivation; inter-language talk; vocational college; business English major

\section{INTRODUCTION}

It is generally believed that there has a close association between motivation and second or foreign language learning, and that a successful language learner is usually highly motivated [1]. Gardner's Socio-educational Model and Dörnyei's three-level framework both contribute a great deal to motivation research. Gardner (1985) presents that motivation involves four aspects: goal, effortful behavior, desire to attain the goal and favorable attitude towards the activity in question. Gardner's proposal insists that motivation should be influenced by two orientations: integrative orientation and instrumental orientation. However, there are few researches to have been done on motivation and oral English competence development [2].

Inter-language talk has been a main way to improve vocational college English majors' oral English competence because of the limit learning environment. Thus, this thesis puts emphasis on the correlation between motivation and English competence development in inter-language talk which does the research on vocational college English majors from the aspects of motivational orientation, desire, attitude and effort according to the model of Gardner.
This paper mainly attaches importance on two questions: the motivation of learners' in the context of inter-language talk is (a) to see whether the vocational college English majors are motivated to develop their English competence in interlanguage talk and whether they are extrinsically or intrinsically motivated; (b) to prove developing English competence in inter-language talk is positively correlated to oral English achievement.

\section{The Relative Theories OF Motivation IN INTER- LANGUAGE TALK}

Gardner's socio-educational model, Dörnyei’s three-level framework and the intrinsic and extrinsic dichotomy give out views of motivation from psychological, cognitive and social constructivist aspects [3]. According to the features of vocational college business English majors' inter-language talk, the following theories are drawn the attention to more scholars.

\section{A. Psychological Approach to Motivation}

a)Integrative and instrumental motivations in SLA

According to Gardner and Lambert, motivation is influenced by two attitudes: attitude to the people who speak the target language, and the attitude to the practical use to which the learner assumes he/she can put the language being learned.

Learning a second language almost in ways involves a combination of external and internal regulatory factors, Noels and her colleagues who have published many works and set out to explore how the orientations proposed by self-determination theory relate to various orientations that have traditionally been identified in the second language field, such as instrumental and integrative.

\section{b) Maslow's need theory}

Maslow's need theory is considered the most popular view, which is distinguished five classes of needs: physiological needs, safety needs, belongingness needs, esteem needs, and self-actualization needs [4]. 


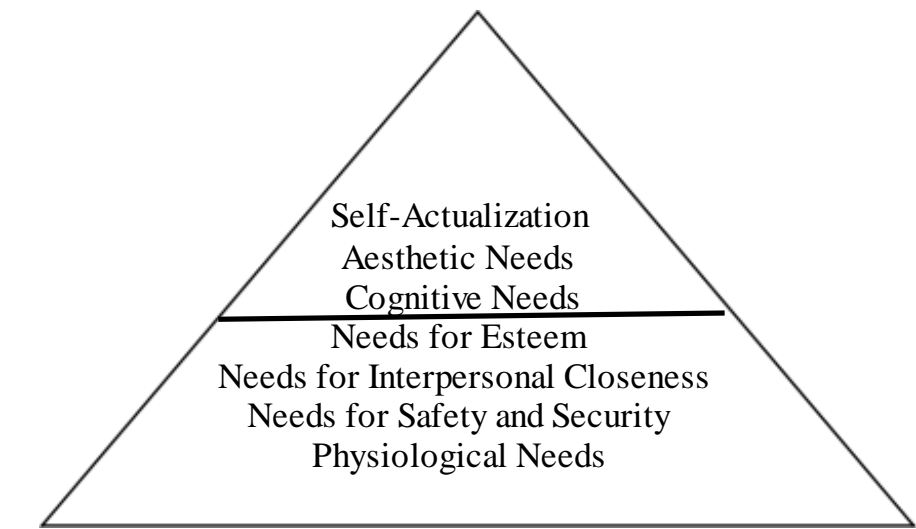

Fig. 1. Maslow's hierarchy of needs

\section{B. Cognitive Approach to Motivation}

\section{a) Self-confidence theories in L2 motivation research}

Self-confidence in general refers to the belief that a person has the ability to produce results, accomplish goals or perform tasks competently. It is used in a more general sense: selfefficacy is always specific to a concrete task whereas selfconfidence is usually used to refer to a generalized perception of one's coping potentials, relevant to a range of tasks and subject domains. Linguistic self-confidence was first introduced in the L2 literature by Clément et al. (1985) to describe a powerful mediating process in multiethnic settings that affects a person's motivation to learn and use the language of the other speech community. Clément and his associates provided evidence that in contexts where different language communities live together, the quality and quantity of the contact between the members will be a major motivational factor in learning the other community's language, determine future desire for communication and the extent of identification with the L2 group[4].

\section{b)Willingness to communicate}

A recent extension of motivation research that has both theoretical and practical potential involves the study of L2 speakers' willingness to engage in the act of L2 communication. It includes linguistic self-confidence, the desire to affiliate with a person, interpersonal motivation, intergroup attitudes, motivation, climate, parameters of the social situation, communicative competence and experience, and various personality traits [5].

\section{c)Self-regulation in L2 motivation research}

This is an intriguing new area within motivational research, exploring ways in which learners can be endowed with appropriate knowledge and skills to motivate themselves. Motivational self-regulation involves self-management skills that help to overcome environmental distractions and completion emotional or physical needs or states. Ushioda has conducted some pioneering analyses of the positive motivational thinking patterns that help someone to keep going even in adverse learning conditions, and on the basis of Corno and Kanfer's (1993) typologies, Dörnyei has proposed a taxonomy of self-motivating strategies made up of five main classes: commitment control strategies, metacognitive control strategies, satiety control strategies, emotion control strategies, and environmental control strategies [3].

\section{Social Constructivist Approach to Motivation}

\section{a)Zone of proximal development}

The internalization of social interactive processes happens in the 'zone of proximal development', i.e., the interactional space within which a learner is enabled to perform a talk beyond his or her own current level of competence, through assisted performance. Thus, learning is ahead of development. Internal mental activity has its origins in external dialogue activity. As the following shows: external/social speech $\rightarrow$ egocentric/private speech $\rightarrow$ inner speech/verbal thought [6].

\section{b) Group dynamics-bringing up competitiveness.}

According to L. Kurt's group dynamic theory, there was a model of how the learner's self-image in comparisons with other L2 learners can either impair or enhance SLA. Where the comparison results in an unsuccessful self-image, there may be debilitating or facilitating anxiety. In the case of the former, learners may reduce or abandon learning effort. In the case of the latter, learners increase their efforts in order to compare more favorably with other learners, and, as a result, learning is enhanced.

\section{The Methodology fOR the Research}

This paper focuses on the three questions in inter-language talk which creates the research on the vocational college business English students in China. Thus, in this investigation, it presents the motivation questionnaire for the students of the vocational college business English majors based on the Attitude/Motivation Test Batery or AMTB. It is aimed at investigating to business English majors' motivation in interlanguage talk. The interview themes are focused on (1) the subjects' initial motivation and persistence to learn English, (2) the subjects' opinions on the pair-work, group discussion and role play to develop their English competence, (3) the subjects' positive and negative ideas of communicating with others, (4) and the subjects' experiences in correlation between their English competence in inter-language talk and English achievement.

As a result, the motivational orientations of vocational college business English majors' inter-language talk are as followings: (1) Intrinsic motivation. 58.64 percent students somewhat agree that they learn English for their language interests and 16.13 percent students have strongly agreement on learning English by its interest. There are about 61.29 percent students interested in English because they like it. (2) Extrinsic motivation. Extrinsic motivation makes the learners less willing to communicate in second language. In interlanguage talk, the subjects are mainly intrinsically motivated but they don't deny extrinsic motivation either, which could also foster their interest and enthusiasm on purpose so as to arouse their intrinsic motivation. However, among various types of regulations existing in the extrinsic motivation in interlanguage talk, the obvious two is identified regulation and integrated regulation. 
TABLE I. MOTIVATION ORIENTATIONS

\begin{tabular}{|c|c|c|c|c|c|c|c|c|c|}
\hline \multirow{2}{*}{\multicolumn{2}{|c|}{$\begin{array}{c}\text { Motivational } \\
\text { factors }\end{array}$}} & \multirow{3}{*}{$\begin{array}{c}\text { Items } \\
\text { A1 }\end{array}$} & \multicolumn{7}{|c|}{ Options of the students' and the percentage of the students making in each option } \\
\hline & & & \multirow{2}{*}{$\begin{array}{c}\begin{array}{c}\text { Strongly } \\
\text { agree }\end{array} \\
36.12\end{array}$} & \multirow{2}{*}{$\begin{array}{c}\text { Some- } \\
\text { what } \\
\text { agree } \\
58.54\end{array}$} & \multirow{2}{*}{$\begin{array}{c}\text { Neutral } \\
1.94\end{array}$} & \multirow{2}{*}{$\begin{array}{c}\begin{array}{c}\text { Some- } \\
\text { what } \\
\text { Disagree }\end{array} \\
3.31\end{array}$} & \multirow{2}{*}{$\begin{array}{c}\begin{array}{c}\text { Strongly } \\
\text { disagree }\end{array} \\
0.00\end{array}$} & \multirow{2}{*}{$\begin{array}{l}\text { Mean } \\
5.104\end{array}$} & \multirow{2}{*}{$\begin{array}{c}\text { S.D. } \\
1.52063\end{array}$} \\
\hline \multirow{6}{*}{ 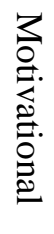 } & \multirow{5}{*}{ 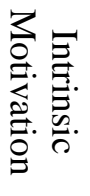 } & & & & & & & & \\
\hline & & A2 & 16.45 & 61.61 & 12.26 & 3.46 & 6.22 & 5.129 & 1.43520 \\
\hline & & A3 & 9.68 & 61.29 & 16.13 & 6.45 & 6.45 & 5.613 & 1.51546 \\
\hline & & A4 & 35.48 & 54.84 & 6.45 & 3.23 & 0.00 & 6.026 & 1.02591 \\
\hline & & A5 & 41.94 & 51.61 & 3.22 & 0.00 & 3.23 & 4.290 & 1.55542 \\
\hline & \multirow{7}{*}{ 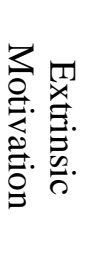 } & A6 & 0.00 & 9.68 & 29.03 & 48.39 & 12.90 & 2.355 & 1.45216 \\
\hline \multirow{6}{*}{. } & & A7 & 20.00 & 60.00 & 13.33 & 6.67 & 0.00 & 4.733 & 1.90512 \\
\hline & & A8 & 3.33 & 26.66 & 50.00 & 13.33 & 3.34 & 3.043 & 1.32451 \\
\hline & & A9 & 0.00 & 39.04 & 38.33 & 20.30 & 3.03 & 3.133 & 1.34803 \\
\hline & & A10 & 13.33 & $\begin{array}{l}63.03 \\
\end{array}$ & 20.30 & 3.33 & 0.00 & 4.083 & 1.45611 \\
\hline & & A11 & 0.37 & 6.63 & 16.37 & 37.00 & 36.63 & 2.101 & 1.73410 \\
\hline & & A12 & 2.32 & 21.29 & 22.90 & 33.23 & 10.26 & 3.032 & 1.55421 \\
\hline
\end{tabular}

Secondly, motivation types of business English majors in inter-language talk are mainly interest factors, development motivation, achievement motivation, self-regulation motivation and going abroad motivation. Therefore, the vocational college business English majors have rather strong desires to develop their competence in inter-language talk and have less anxiety. They are willing to communicate and desire to affiliate with a person to show interpersonal relationship and communicative competence and experience.

TABLE II. DESIRE IN INTER-LANGUAGE TALK

\begin{tabular}{|c|c|c|c|c|c|c|c|c|}
\hline \multirow{5}{*}{$\begin{array}{c}\text { Desire in } \\
\text { interlanguage } \\
\text { talk }\end{array}$} & B1 & 41.61 & 54.84 & 3.23 & 0.32 & 0.00 & 5.387 & 1.26833 \\
\cline { 2 - 8 } & B2 & 35.48 & 44.16 & 19.23 & 1.02 & 0.30 & 5.161 & 1.39029 \\
\cline { 2 - 8 } & B3 & 22.58 & 41.94 & 32.15 & 3.22 & 0.11 & 3.774 & 1.52436 \\
\cline { 2 - 8 } & B4 & 19.35 & 51.61 & 21.58 & 1.01 & 3.22 & 4.806 & 1.32777 \\
\cline { 2 - 8 } & B5 & 2.26 & 6.45 & 30 & 54.84 & 6.45 & 2.452 & 1.75423 \\
\cline { 2 - 9 } & B6 & 0.00 & 2.23 & 16.13 & 71.97 & 9.68 & 2.129 & 1.76512 \\
\cline { 2 - 9 } & B7 & 12.90 & 54.84 & 29.03 & 3.23 & 0.00 & 4.874 & 1.47925 \\
\cline { 2 - 9 } & B8 & 3.22 & 45.16 & 31.15 & 19.35 & 1.10 & 3.323 & 1.65721 \\
\hline
\end{tabular}

Thirdly, attitude toward competence development of interlanguage talk proves a common phenomenon existing in vocational college business English majors that the teachers' teaching method, pronunciation and comprehensible input are one of the necessary factors to affect their attitudes. VCVEMs agree that the efficient directions from teacher play an important role in inter-language talk and lively teaching method can strengthen learner's interests and attitudes. Besides, the subjects insist that they should have less time to talk with their peers. Actually, the more comprehensible input they get, the faster their speed learning oral English could be. And the inter-language talk among the peers of VCVEMs can be more efficient and useful.

TABLE III. ATTITUDE IN INTER-LANGUAGE TALK

\begin{tabular}{|c|c|c|c|c|c|c|c|c|}
\hline \multirow{5}{*}{$\begin{array}{c}\text { Attitude } \\
\text { in } \\
\text { inter-language } \\
\text { talk }\end{array}$} & C1 & 32.25 & 58.06 & 6.45 & 0.00 & 3.22 & 4.161 & 1.54627 \\
\hline & C2 & 51.61 & 41.90 & 6.45 & 0.036 & 0.00 & 4.823 & 1.47925 \\
\hline & C3 & 32.26 & 54.84 & 9.68 & 3.12 & 0.11 & 5.161 & 1.30312 \\
\hline & $\mathrm{C} 4$ & 22.58 & 35.48 & 32.26 & 9.43 & 0.25 & 3.910 & 1.58622 \\
\hline & C5 & 9.68 & 45.01 & 19.35 & 25.81 & 0.15 & 3.387 & 1.61058 \\
\hline
\end{tabular}

Fifthly, the effort for competence development shows that the average subjects of VCVEMs have the consciousness to practice their oral English through inter-language talk. But because of the environment and conditions, such as indifference from others and no correct partners etc. some students just have no chance to practice with others. On the other hand, some are involved in other affaires which make them ignore to communicate with others insistently. To sum up, effort of VCVEMs to competence development in interlanguage talk are conscious, but lack of persistence. 
TABLE IV. ATTITUDE IN INTER-LANGUAGE TALK

\begin{tabular}{|c|c|c|c|c|c|c|c|c|}
\hline \multirow{3}{*}{$\begin{array}{c}\text { Effort in inter- } \\
\text { language talk }\end{array}$} & D1 & 6.45 & 16.13 & 32.60 & 22.58 & 22.24 & 2.161 & 1.46833 \\
\cline { 2 - 9 } & D2 & 2.23 & 4.23 & 29.03 & 21.58 & 42.93 & 1.677 & 1.74687 \\
\cline { 2 - 9 } & D3 & 6.45 & 35.48 & 12.90 & 6.45 & 38.72 & 2.258 & 1.51899 \\
\cline { 2 - 9 } & D4 & 0.00 & 9.03 & 33.34 & 51.70 & 5.93 & 1.506 & 1.69851 \\
\hline
\end{tabular}

(Notes: IM=Intrinsic Motivation; EM=Extrinsic Motivation; S.D: Standard Deviation SA: Strongly Agree; SA: Somewhat Agree; N: Neutral; SD: Somewhat Disagree; SD: Strongly Disagree.)

\section{Pedagogic Implications}

\section{A. Promoting Motivation Through Cooperative Learning}

Cooperative learning is the instructional use of small groups in which students work together to maximize their learning, as well as their group members. Cooperative learning will reduce anxiety; cooperative learning promotes interaction and social skills; cooperative learning increases learners' selfconfidence and self-esteem; cooperative learning increases support for language learners to move from interdependence to independence. Cooperative learning requires interaction and negotiation between members of the group. Cooperative learning has gained wide spread use in language classrooms around the world because of the positive affective classroom climate it creates and its potential for providing supportive and more opportunities for learners to use the language.

\section{B. More Opportunities to Connect Language Competence to Performance}

Bakintin's dialogism provides a bridge between the learner's external and internal realities.

That is, the external world affects and transforms the individual's mental functioning, which, in turn, affects and transforms social, cultural, and institutional settings. They think there would not be any separation between language competence and language performance, which is significant for second language learners to improve their oral English.

\section{Reducing Anxiety and Constructing Expectancy-value}

If people are anxious, but allowed to affiliate, their anxiety level is reduced. Greater likelihood of success reduces anxiety and results in promoted participation and language learning. By encouraging the UEMs to talk by interlanguage, cooperative activities build greater confidence and self-esteem than is likely in a competitive environment, where self-validation is dependent upon a continuing need to demonstrate success [7]. An increase in self-confidence and self-esteem will lead to increased learners' efforts in learning language and a greater willingness to take risks or to continue attempts to make one's views understood. Thus, reducing anxiety and constructing expectancy-value will enhance intrinsic motivation in interlanguage talk.

\section{Familiarizing Learners with Target Language Culture}

In most studies, learners cannot find a suitable topic to talk to their partners. They don't have enough culture or knowledge to exchange. So it is necessary to improve their social culture background. And learners exposed to CL were more likely than learners' under competitive individualistic condition to name a classmate from a different group, or social class as a friend. In the practice of CL, learners develop their communicative skills and friendship. In the interview during my experiment, the learners reported that they were more likely than other students to use the cooperative behaviors they were motivated when they worked with other peers.

\section{E. Providing Comprehensible Input and Improving Learners' Autonomy}

Providing comprehensible input can help the learners promote their interests, correct attitude to English learning a higher motivation. Besides, achievement appears to be closely linked to self-determination. Students should be made clear that language can't be taught but only learned, and that learners need to develop autonomy, not dependence [8]. Students should do everything by themselves virtually and communicate with others actively. They should foster autonomy on English learning. The teachers should give students responsibility and help them to know that success requires efforts, so as to increase their intrinsic motivation. Teachers can share responsibilities with the students for organizing their time, effort and learning process; invite students to design and prepare activities themselves; promote peer teaching; carry out project work which students are in charge of; and give students positions of genuine authority.

\section{CONCLUSION}

As a result of the findings, analysis and discussion, the aspects of orientations, desire, attitude and effort are exactly studied. It has demonstrated that the university English majors are motivated to develop their English competence in interlanguage talk and they are or more intrinsically motivated than extrinsically motivated. It also in terms of the questionnaire concludes out the main motivation types of university English majors in inter-language talk: interest motivation, development motivation, achievement motivating, self-efficacy motivation and going abroad motivation. On the other hand, the survey comes to the conclusion that the correlation between the motivation and English competence in inter-language talk is positive in terms of correlation analysis among motivation factors: extrinsic motivation, intrinsic motivation, desire, attitude and efforts. As it proves, the research objectives are arrived at a conclusion according to the results of this chapter.

\section{ACKNOWLEDGEMENT}

The author appreciates all of her co-workers for the work and the students who answer the questionnaire carefully. 


\section{REFERENCES}

[1] L. Vandergrift, "Relationships among Motivation Orientations, Metacognitive Awareness and Proficiency in L2 Listening”, Applied Linguistics, vol. 26, pp. pp.70-89, 2005.

[2] R. C. Gardner, Social Psychology and Language Learning: The Role of Attitudes and Motivation. Edward Arnold, London, 1985.

[3] Z. Dörnyei, Teaching and Researching Motivation, Beijing: Foreign Language Teaching and Research Press, 2005.

[4] R, Clément, Z. Dörnyei., \& K. A. Noels. 1994. "Motivation, Selfconfidence and Group Cohesion in the Foreign Language Classroom”, Language Learning, vol. 44, pp.417-448, 1994.
[5] A. H. Maslow, Motivation and Personality (2nd edition). Harper \& Row: New York, 1970.

[6] V. K. Zaretskii. "The Zone of Proximal Development What Vygotsky Did Not Have Time to Write”, Journal of Russian and East European Psychology, vol.47, pp. 70-93, 2009.

[7] R. E. Slavin, Cooperative learning: The social psychology of the primary school. N.Y.: KKY, 1990.

[8] H. D. Brown, "Principles of Language Learning and Teaching Strategies,” J. Applied Linguistics, pp.155-262, 1994. 